\title{
A cultura sanitária a partir da perspectiva da história oral: o Sertão do Rio Doce em suas múltiplas percepções temporo-espaciais
}

\author{
Patrícia Falco Genovez ${ }^{1}$ \\ Maria Terezinha Bretas Vilarino²
}

Introdução: a temática

e suas articulações conceituais básicas

Uma reflexão sobre a cultura sanitária do Sertão do Rio Doce, a partir da História Oral, permite-nos pensar em dois percursos: o primeiro remonta à discussão sobre o termo "sertão", tratado pela historiografia; e o segundo busca uma aproximaçáo da forma como os próprios sertanejos o definem e o vivenciam a partir de suas narrativas. Esse último percurso será tomado como um exercício para pensarmos o Sertâo para além do discurso historiográfico, lembrando que o próprio termo possui um sentido e um significado inerentes à perspectiva daqueles que cotidianamente o vivenciam.

Portanto, o segundo percurso vincula a esse cenário a introdução da cultura sanitária, através da narrativa e da ação do Serviço Especial de Saúde

1 Univale. Doutora em História - UFF.

2 Univale. Doutoranda em História - UFMG. 
Pública (SESP). Nesse aspecto, esse percurso implica um recorte espacial circunscrito à cidade de Governador Valadares, localizada a leste de Minas Gerais e considerada como polo da região do Médio Rio Doce desde as primeiras décadas do século XX. A cidade polo em questão, assim como a esmagadora maioria das cidades e distritos do Sertão de Minas Gerais, apresentava um cenário calamitoso, permeado por endemias, epidemias e ausência quase completa dos princípios básicos de saneamento. No início da década de 40, a partir de um acordo bilateral entre Estados Unidos e Brasil, iniciou-se um projeto de saneamento do Médio Rio Doce - área considerada estratégica para a extração de vários minérios largamente utilizados em artefatos bélicos.

Nesse sentido, a História Oral será incorporada a esse exercício enquanto metodologia de coleta e processamento de narrativas. $\mathrm{O}$ esforço metodológico em atrelar o método histórico ao etnográfico, proporcionando uma aproximação entre a Antropologia e a História, corrobora o perfil de um historiador etnográfico que busca, através da pesquisa, acessar a maneira pela qual as pessoas compreendiam o mundo em que viviam, lembrando Robert Darnton (1996, p. 14). Dentro dessa perspectiva, as fontes orais vêm recuperando testemunhos até então relegados ao anonimato ou à simples exclusão. Assim, enquanto coleta de testemunhos, a História Oral produz narrativas orais e, por conseguinte, narrativas de memória que estabelecem alteridade e identidade (Errante, 2000, p. 142).

Ao acessar memórias, a História Oral também entrelaça categorias distintas, tecendo uma trama complexa envolvendo a memória, a história, o tempo e o espaço. Essas duas últimas categorias são esteios das identidades e suporte do ser no mundo. Em outras palavras, "se o espaço se transforma e as referências espaciais se perdem na dinâmica incessante do tempo, os homens perdem seus elos, sua base identitária e a substância de sua história" (Delgado, 2003, p. 14). Nos dizeres de Certeau (2011, p. 182), "as estruturas narrativas têm valor de sintaxes espaciais”. É dessa forma que a memória navega, ancorando-se no espaço, uma vez que se constitui em meio a um fluxo de tempo distinto, não linear e múltiplo (Harvey, 1993, p. 201). Por isso, é fundamental reconhecer suas motivaçóes simbólicas sem perder de vista suas figuraçôes diferenciadas. Numa perspectiva antropológica, podemos dizer que a memória não se configura apenas num tradicionalismo nostálgico e sentimental, "mas nos mitos, saberes, fazeres e tradiçôes que são perenizados, 
ordinariamente, no interior das manifestaçóes culturais humanas, a contragosto das intimaçóes objetivas de um devir, numa sequência de fixaçôes no espaço da estabilidade do ser" (Rocha e Eckert, 2000, p. 13).

Há, portanto, que nos referirmos à produção de territórios existenciais (Elhajji, 2002, p. 179). Tais territórios existenciais seriam configurados a partir de um habitus espacial, transmitido através do processo de socialização. É o habitus espacial que "determina os modos de percepção, de representação, de elaboração e de semantização do espaço pelo indivíduo, em conformidade com a visão global do mundo própria ao seu grupo cultural" (Elhajji, 2002, p. 182). Halbwachs (1990), ao trabalhar a memória social, expressou o quanto é difícil modificar as relaçóes estabelecidas entre os homens e as pedras.

Quando um grupo humano vive muito tempo em lugar adaptado a seus hábitos, não somente os seus movimentos, mas também seus pensamentos se regulam pela sucessão das imagens que lhe representam os objetos exteriores. Nossas impressóes se sucedem, uma à outra, nada permanece em nosso espírito, e não seria possível compreender que pudéssemos recuperar o passado, se ele náo se conservasse, com efeito, no meio material que nos cerca. É sobre o espaço, sobre o nosso espaço - aquele que ocupamos, por onde passamos, ao qual sempre temos acesso, e que em todo o caso, nossa imaginação ou nosso pensamento é a cada momento capaz de reconstruir - que devemos voltar nossa atençáo; é sobre ele que nosso pensamento deve se fixar, para que reapareça esta ou aquela categoria de lembranças. (Halbwachs, 1990, p. 143).

É inegável, portanto, o quanto a memória contribui para a constituição de categorias espaciais (Holzer, 2000, p. 111). Essa aproximação é um tanto quanto valorizada pela geografia humanista produzida por Lowenthal (1961), posteriormente retomada por Tuan (1977). Para esse último autor, nossas experiências e aspiraçóes pessoais encarnam-se em lugares que devem ser compreendidos segundo os significados que lhes são conferidos. Contudo, há que se considerar que nessa perspectiva o espaço não aparece como simples representação, associando a este a fixação de significados. ${ }^{3}$

3 Sobre essa questão, Doreen Massey (2009, p. 59) diz: "Talvez a má interpretação do espaço, seu abandono à longínqua escuridão da fixidez e do fechamento, acontecesse, em parte, por causa da reação dos cientistas sociais e filósofos à intransigência da ciência natural na questão do tempo". 
Pelo contrário, o consideraremos de forma dinâmica, tal qual o fluxo temporal, repleto de trajetórias múltiplas e de simultaneidades. Dessa interação, podemos incorporar à nossa reflexão a noção de tempos espaciais, fazendo emergir um espaço praticado, construído de forma relacional.

Se o tempo se revela como mudança, então o espaço se revela como interaçáo. Neste sentido, o espaço é a dimensáo social não no sentido da sociabilidade exclusivamente humana, mas no sentido do envolvimento dentro de uma multiplicidade. Trata-se da esfera da produção contínua e da reconfiguraçáo da heterogeneidade, sob todas as suas formas - diversidade, subordinação, interesses conflitantes. (Massey, 2009, p. 97 e 98)

É em virtude da trama complexa tecida entre as categorias anteriormente expressas - a memória, a história, o tempo e o espaço - que nos parece oportuno agregar outras perspectivas de conhecimento. Consideramos que ambos os percursos, propostos no início deste artigo, incitam a necessidade de agregarmos a sociologia figuracional expressa em várias obras de Norbert Elias $(1990,1994,1998,2000,2001)$ à perspectiva histórica, haja vista que tanto uma dada percepçáo de representaçáo do sertão - espaço que uma vez significado se transforma em território - quanto o efetivo saneamento da cidade de Governador Valadares e da regiáo do Médio Rio Doce envolvem consideraçóes; no primeiro caso, do discurso alavancado pela historiografia; e, no segundo, do discurso desenvolvido pelo SESP, relacionando perspectivas e figuraçôes de mundo bastante diversas.

Ao considerar a perspectiva de tempos espaciais que rompe com a noção estática e aprisionada da representação do Sertão, é possível nos aproximarmos da percepção elisiana da sociedade. Essa percepção pode nos fornecer uma interessante chave de leitura, haja vista que Elias considera a sociedade como um conjunto incessantemente renovável da interdependência entre os indivíduos, relaçóes que não cessam de se modificar e evoluir, atravessadas por tensôes e conflitos que conduzem a desequilíbrios e a formas provisórias de integração. Atrelamos esse movimento incessante a um espaço que, longe de ser estático e mera representação, torna-se cenário móvel dessa interação. Assim, o conceito elisiano de figuração, definido como redes formadas por seres humanos interdependentes, acompanhadas por mudanças assimétricas na balança de poder, enfatiza o caráter processual e dinâmico das redes cria- 
das pelos indivíduos. Essa perspectiva nos fornece elementos que recolocam o cotidiano de tais redes num patamar privilegiado e, por conseguinte, a História Oral como um importante instrumento de acesso aos mais variados tempos espaciais vivenciados pelas diversas redes sociais.

As narrativas (histórias produzidas pelo senso comum) e o discurso (produzido ideologicamente) inter-relacionaram-se com a ação e a relação social em curso. Por sua vez, tais relaçóes remarcaram e reordenaram um dado espaço, recortado e organizado conforme territorialidades estabelecidas e/ ou (re)criadas. Nesse sentido, a sociologia figuracional elisiana aproxima-se da sociologia compreensiva weberiana na busca da especificidade da realidade que nos rodeia, "e na qual nós encontramos a conexão e a significação cultural de suas diversas manifestaçóes em sua configuração atual, de um lado, e as razóes que fizeram com que historicamente ela se desenvolvesse sob esta forma e náo sob outra, de outro lado" (Colliot-Thélène, 1995, p. 26).

A ação social desenhada por Weber é uma modalidade específica de conduta à qual o próprio agente associa um sentido, objetivamente visado por este e que se manifesta em açóes concretas, fundamentadas por um motivo. $\mathrm{O}$ vínculo motivacional fornece uma dimensão processual à açáo social em vez de analisá-la como ato isolado, com uma sequência definida de elos significativos, formando o que o autor identifica como uma 'cadeia motivacional'. Para além do conceito de ação social, Weber propóe um desdobramento no intuito de avançar para além do individual: o conceito de relação social. Esse último conceito se refere "à conduta de múltiplos agentes que se orientam reciprocamente em conformidade com um conteúdo específico do próprio sentido das suas açóes” (Cohn, 1991, p. 26 a 30). A diferença básica entre esses conceitos está no fato de que, no primeiro, a conduta é orientada significativamente pela conduta de outro(s), enquanto, no segundo, a conduta de cada agente é orientada por um sentido reciprocamente partilhado.

Partindo desses pressupostos, a análise da cultura com base numa visão mais ampla, e com a possibilidade de compreensão da ação social e da relação social, permite-nos uma melhor apreensão da conduta dos múltiplos agentes e dos significados que estes venham a ganhar. É necessário, para tanto, estender a análise para a antropologia interpretativa, segundo a qual cultura é compreendida como uma 'teia de significados'. Com base nesses pressupostos, todo indivíduo é compreendido a partir desses 
significados, cuja teia é a cultura (Geertz, 1978, p. 15). Trabalharemos, portanto, nessa perspectiva, entendendo o trabalho etnográfico sempre atrelado à metodologia da História Oral. Assim, ambas as metodologias se aproximam com o estabelecimento de relaçóes, a seleção de informantes, a transcrição de textos, o mapeamento de campo, a manutenção de diários e, fundamentalmente, como esforço intelectual para chegar, enfim, a tecer etnograficamente o que Geertz chama de descrição densa, num processo posterior de coleta em que as estruturas significantes aparecem em meio a percepçóes que devem ser apreendidas. Nesse sentido, o fazer etnográfico tem a conotação de uma construção que traz como central construir uma leitura de significados expressos de diversas formas, como "um manuscrito estranho, desbotado, cheio de elipses, incoerências, emendas suspeitas e comentários tendenciosos, escrito não com os sinais convencionais do som, mas com exemplos transitórios de comportamento modelado" (Geertz, 1978, p. 15).

Alcançar a teia de significados proposta pela Antropologia Interpretativa sugere uma aproximação com alguns pressupostos da Psicologia Cultural, cuja intenção tem sido "mostrar como os seres humanos, em suas interaçóes, formam uma noção do canônico e do comum como um pano de fundo contra o qual interpretam e dão significado narrativo às violaçóes e afastamentos de estados 'normais' da condição humana” (Bruner, 1997, p. 65). Todo o processo ocorre mediante uma negociação dos significados por intermédio da interpretação narrativa armazenada por uma comunidade. A memória da narrativa remete-nos à mesma questáo proposta por Paul Ricoeur ao mostrar sua inquietaçáo com o próprio campo de investigação: "importa ao historiador saber qual é seu contraponto, a memória dos protagonistas da ação tomados um a um, ou a das coletividades tomadas em conjunto?” (Ricoeur, 2007, p. 105). O desafio será, portanto, como bem coloca Ricoeur, lançar-se ao problema de revelar as relaçóes internas entre a memória coletiva e a memória individual.

Nesse ponto, ressalta-se a contribuição de Elias ao favorecer o rompimento com a dicotomia indivíduo/sociedade. Sua perspectiva relacional e interdisciplinar da sociedade prioriza a síntese em relação à análise. A figuração elisiana diz respeito a pessoas que estão continuamente em fluxo e vivenciam mudanças de ordem diversas, sejam rápidas ou lentas, superficiais ou profundas. Tais processos apresentam dinâmicas próprias, nas quais 
as razões individuais não se reduzem a questões isoladas. Faz-se necessário compreender e interpretar as figuraçóes a partir das redes formadas por indivíduos interdependentes, enfatizando seu caráter processual e dinâmico. Em outras palavras, não há como separar individuo e sociedade. $\mathrm{O}$ indivíduo é gerado pelos seus antecessores e faz parte de um todo social, constituído como uma rede de funçôes, cujo contrato social resulta de uma ligação funcional preexistente que estrutura os acordos cumulativos. Esse contrato estabelece as funçóes interdependentes dos sujeitos envoltas em relaçóes de poder (Elias, 1994). Tomaremos essa chave de leitura para desvendar, através das interpretaçóes narrativas, em suas várias teias de significado, os vários tempos-espaciais que permeiam o território real, múltiplo e recortado por inúmeras territorialidades que caracterizaram o Sertão do Rio Doce.

Cabe, nesse sentido, esclarecer que a multiplicidade de narrativas às quais nos referimos se aproximam da ideia de polifonia e que esta incorpora o elemento central da teoria da linguagem, a palavra do outro. De acordo com essa perspectiva polifônica, a intençáo é buscar a unidade dos contrários (Bakhtin, 2002). Muito embora a proposta deste trabalho não seja uma análise linguística das narrativas sobre a cultura sanitária, consideramos importante pensá-las numa perspectiva polifônica, uma vez que, tal como no romance de Dostoievski, percebemos uma multiplicidade de vozes que se entrechocam e manifestam diferentes pontos de vista sobre um dado objeto.

São essas inúmeras vozes que darão dinâmica às territorialidades. Nesse sentido, ressaltamos que a noçáo de multiterritorialidades que trazemos para esta análise é a de Rogério Haesbaert (2006). Dentro dessa concepção geográfica, o território relacional encontra-se imerso num contexto sócio-histórico permeado por relaçóes de poder. A territorialidade é compreendida como o controle de pessoas e/ou recursos e como uma estratégia espacial para atingir, influenciar ou controlar recursos e pessoas, podendo ser ativada ou desativada (Sack, 1986). Nesse espaço, devidamente apropriado e significado que se transforma em território, o Médio Rio Doce é percebido, ainda na primeira metade do século XX, como Sertão. Iniciamos, portanto, nosso primeiro percurso, sem, contudo, tomá-lo exaustivamente, tendo em vista que ele apenas nos fornecerá o cenário no qual se encontra inserida a cultura sanitária. 


\section{O Sertão dos discursos historiográficos e suas múltiplas faces do vivido}

Na perspectiva de Alexandre Cunha (2002), o sertão pode ser compreendido como uma categoria de percepçáo geográfica que distinguia as regióes mais distantes e ermas do centro da província de Minas nos séculos XVIII e XIX. Enquanto categoria, o sertão está relacionado a uma dada percepçáo da natureza que se faz diversa e apartada do conhecido. Numa perspectiva histórica, o sertấo em Minas Gerais passou a designar a grande área ao norte do território e as áreas com presença de gentio, como, por exemplo, os bravios botocudos, na altura do Rio Doce.

Além de categoria espacial, sertáo também pode ser pensado como uma categoria do pensamento social brasileiro e como categoria cultural, conforme Janaína Amado. Em suma, nas palavras da autora, "são regiốes em processo de conquista e de integração à nação, onde foi comum duas ou mais culturas se encontrarem ou se enfrentarem" (Amado, 1995, p. 51).

Nísia Trindade Lima problematiza a imagem de sertão presente no pensamento social brasileiro da primeira república: se, por um lado, se apresenta com a imagem de um "território do vazio, o domínio do desconhecido, o espaço ainda não preenchido pela colonizaçáo [...] o mundo da desordem, domínio da barbárie, da selvageria, do diabo" (Lima, 1999, p. 57); por outro, uma vez que o Sertão se torna conhecido, passa a ser ordenado a partir de um processo de ocupação e colonização, tornando-se região colonial. Ao transformar-se em divisão geográfica pela colonizaçáo, o sertão vira, também, sinônimo de fronteira. Assim, essas "representaçóes tornam-se paradigmáticas para se pensar a natureza das sociedades e o tema da identidade nacional" (Lima, 1999, p. 44). No enredo percorrido, ficam explícitas as dualidades constitutivas do pensamento social acerca de temáticas como natureza/barbárie, sertão/litoral, atraso/modernidade.

No que diz respeito ao Sertão do Rio Doce, desde o século XIX, mantinha-se a percepção de "lugar do estranho, habitado por quem não participava da lógica da colonização" (Espindola, 2005, p. 75). Mas, além dessa construção simbólica, construiu-se o mito da riqueza nos lugares contíguos do Rio Doce, nas palavras de Diogo de Vasconcelos. No início do século XX, Nélson de Senna financiou uma expedição de reconhecimento do rio 
e realçava as extraordinárias riquezas adormecidas à espera da indústria extrativa (Espindola, 2005, p. 98). ${ }^{4}$ A empreitada pela ocupação territorial do Sertáo do Rio Doce perdurou por todo o século XIX e avançou às primeiras décadas do século XX. Se para o século XIX, a região do Rio Doce era "terra de promissáo”, de riqueza a descobrir e explorar, vencendo-se a floresta e abrasileirando-se os habitantes indígenas, para meados do século XX, a viabilidade da exploração econômica dos recursos naturais nela identificados carecia do saneamento, da abertura de vias de comunicação e acesso, da integração daquele território à nação brasileira.

As narrativas de três depoentes reconfiguram, de certa forma, as percepçóes oriundas do século XIX, muito embora tenham chegado à cidade de Governador Valadares na década de 1940. Nosso depoente 1 é médico, natural de Manhuaçu. Ele conta que ao chegar à cidade de Governador Valadares teve a impressão de estar desembarcando no Congo. Recordou-se de que foram necessários três dias de viagem, passando por Cachoeiro do Itapemirim, depois por Vitória e, finalmente, após um dia de viagem de trem, chegou a Valadares. Um percurso que hoje é feito em menos de quatro horas, mas que na ocasiáo exigiu travessias de canoa e um dia de viagem numa Maria Fumaça que cruzava as matas pelo caminho. Os tempos eram de guerra (década de 1940), e o trem de passageiros tinha que parar muitas vezes para dar preferência aos de carga. $\mathrm{Na}$ bagagem, nosso informante levava "máscara de anestesia, medicamentos, livros, etc., uma tourada verdadeira". Mas a condição do Sertão, com todas as suas dificuldades, e até certo exotismo, nos é contada com a história do primeiro grande desafio do jovem doutor: uma apendicite, diagnosticada em um dos alunos internos no colégio onde seu irmão era diretor. A noite chuvosa, a falta de equipamentos adequados, o risco de uma cirurgia naquelas circunstâncias e o treinamento obtido em um pronto-socorro do Rio de Janeiro, onde havia se formado, dá uma pálida dimensão do que de fato era estar no Sertão. Sem nenhum médico experiente que pudesse auxiliar no procedimento, o depoente fez o que podia e esperou que Alá fizesse o resto...

E Alá ajudou, que o menino escapou. Nesse tempo os micróbios ainda não sabiam dissolver os antibióticos ou os quimioterápicos. Então, o menino,

4 Diogo de Vasconcelos e Nélson de Senna são autores clássicos da historiografia mineira. 
escapou, a palavra é escapar, escapou de mim... Aquilo foi uma zoeira na cidade: chegou um doido aqui que operou com o auxílio de um tacho e fez isso. $\mathrm{O}$ fato é que o menino tá vivo. Naquele tempo os micróbios não conheciam sulfa nem havia sulfa em Valadares. E nós mandamos buscar na ACESITA, em Coronel Fabriciano, onde havia um hospital, conheciam sulfa, e como o micróbio não conhecia, morreu (Depoente 1, 2001).

Nessa breve recordação do depoente, percebemos o quanto o tempo e o espaço se tornam fluidos. Nas açóes dele, o Rio de Janeiro se faz presente no Sertão do Rio Doce, na erma cidade de Governador Valadares. Os tempos da modernidade, do antibiótico e da medicina científica se cruzam com o da tradição. Numa restrita confluência tempo-espacial, ações arrojadas forjaram uma temporalidade diferente, misturando o moderno e o arcaico, o tacho e a anestesia, promovendo uma aproximação estranha dos espaços. $\mathrm{O}$ Rio de Janeiro estava em Governador Valadares; dimensóes espaciais foram remodeladas e espaços transformados: uma sala simples e pequena torna-se centro cirúrgico, e as experiências ocorridas lá, no Rio de Janeiro, estavam cá, em Valadares. O 'Congo' do jovem doutor era ermo, estranho, não 'colonizado', desconhecido, selvagem, mas também era terra de promissão, onde esperava consolidar sua carreira.

Essa história foi apenas o início de uma carreira de muitas dificuldades e de grandes vitórias vivenciadas pelo depoente, mas nos fornece elementos para repensar o Sertão estático, discutido anteriormente. Na historiografia e, muitas vezes, até mesmo na literatura, esse Sertão parecia inacessível e num tempo bem distante. Diversamente, a oralidade da história contada pelo nosso informante nos mostra um Sertão de tempos e espaços entrecruzados, que dialogam e se remodelam a cada instante, atraindo o longínquo, fundindo espacialidades e temporalidades, rompendo a lógica binária e dicotômica da natureza/barbárie, do sertão/litoral, do atraso/modernidade, plasmando uma nova temporalidade em que tudo isso parecia se misturar e se redimensionar.

$\mathrm{Na}$ esteira dessa mistura, as necessidades bélicas da guerra exigiam do governo um esforço de incorporação do Sertâo, especialmente para extração da mica (Espindola, 1998, p. 157). ${ }^{5}$ Foi em um cenário parecido ao do

5 Minério bastante utilizado na indústria elétrica e eletrônica dos países desenvolvidos, a mica ou malacacheta é a designação comum dos minerais do grupo dos silicatos de alumínio e de metais alcalinos aos quais frequentemente se associam magnésio e ferro. 
depoente 1 que nosso outro informante, o depoente 2, dentista formado também no Rio de Janeiro, chegou ao Sertão do Rio Doce. Para ele, a cidade de Valadares não se assemelhava ao 'Congo', mas o que viu levou-o a pensar em "uma reserva ecológica, vamos dizer assim, foi a mais recente fronteira de 50 anos pra cá, que foi aberta em Minas Gerais", cujo grande desafio era vencer o anofelino, o mosquito transmissor da malária. "Ele [o mosquito] guardou isso aqui pra nova geração, pra geração de vocês. Porque eu, eu usufrui, eu tive que desbravar. Vocês já estão colhendo os resultados". Nesse aspecto, todo o Médio Rio Doce é visto como "um patrimônio natural formidável. Quer dizer, as reservas principais, as reservas mineralógicas que deixaram aqui, foram a grande fonte de colonização, com a descoberta da mica como matéria-prima essencial ao esforço da guerra, e a madeira”.

Na visão do depoente 2, o Sertão encontrava-se imerso na temporalidade da natureza plena. $\mathrm{Na}$ floresta desbravada e extinta em apenas algumas poucas décadas, a temporalidade ecológica não só ameaçava como arrebanhava muitas vidas. Era o espaço perigoso a ser desbravado, a fronteira estendida entre a natureza e a civilização. Com a sua chegada, um ano depois do estabelecimento do Serviço Especial de Saúde Pública, trava-se uma batalha de tempo e espaço. A conquista do Sertão novamente mistura essas categorias e torna-as múltiplas e complexas, rompendo mais uma vez com uma percepção projetada pela historiografia. Curiosamente, o Sertão distante, enquanto área não incorporada à nação, não colonizada e fora do compasso da modernidade, parece ter sido avistado apenas pelos de fora, já que, para aqueles que mergulharam nele, uma outra dimensão se desenhava, pontes eram construídas entre espaços até então ermos, a modernidade chegava de forma desconcertante e os tempos eram múltiplos.

É justamente a partir dessa perspectiva de sertão que trataremos a região circunscrita no Médio Rio Doce, cuja cidade polo tem sido, desde o início do século XX, Governador Valadares. É esse espaço ermo, vislumbrado como lugar da riqueza e dos enfrentamentos, dos conflitos e de mortes, entrecortado por inúmeras territorialidades, que tomamos como cenário para o processo de saneamento e atuação do SESP. Cenário esse múltiplo, entrecortado por tempos espaciais, que os depoimentos e entrevistas revelam. 


\section{A cultura sanitária e suas múltiplas percepções temporo-espaciais}

O distante e árido Sertão do Rio Doce, cercado de endemias, também se encontra projetado nos discursos de saneamento, produzidos ideologicamente, e nas narrativas produzidas sem um norteamento ideológico padronizado. Eles foram coletados através de entrevistas concedidas por agentes de saúde do SESP, e que por ora são nossos atores privilegiados nesta análise. Do ponto de vista historiográfico, narrativas desse tipo são significativas, na medida em que apontam para práticas culturais ainda pouco exploradas, complementando a perspectiva das poucas obras dedicadas à história regional e local, dentre as quais destacamos Siman (1988), Borges (1988), Espindola (1998, 1999, 2005) e Vilarino (2008). Ressaltamos que essa produção historiográfica ainda embrionária não chegou a atuar na mentalidade local, a qual permanece amparada pela 'história' produzida por memorialistas nas décadas de 1970-80, e que ainda hoje são considerados como os guardiōes da história 'oficial' da cidade. Daí a importância de se tratar a história do SESP numa perspectiva que coloca a cidade de Governador Valadares sob um novo prisma, atrelando a percepçáo do cotidiano aos variados discursos da realidade e às suas múltiplas territorialidades, o que de fato só faz aumentar a responsabilidade da História Oral em relação à historiografia local.

Mas é importante ressaltar que essas histórias do saneamento em Governador Valadares também envolvem uma farta documentação que merece ser levada em consideraçáo. As informaçôes que se seguem são baseadas na documentação produzida oficialmente pelo SESP, e devem ser aqui tratadas com o intuito de compreendermos melhor os depoimentos e narrativas postulados por servidores e cidadáos que vivenciaram o processo.

Se tomarmos como referencial a narrativa documental, o SESP foi uma agência de saúde pública criada por meio de um acordo bilateral entre os governos do Brasil e dos Estados Unidos em 1942, a partir dos chamados "Acordos de Washington" (Campos, 2006, p. 35). ${ }^{6}$ Um ano depois, o SESP

6 Os Acordos de Washington selaram a aproximação entre os governos do Brasil e dos EUA, bem como a adesão brasileira ao "esforço de guerra" dos aliados contra os países do Eixo durante a Segunda Guerra Mundial. 
iniciava a execução do saneamento do Vale do Rio Doce com o objetivo claro de resolver os problemas das endemias. O objetivo de "implementar políticas sanitárias em áreas econômica e militarmente estratégicas” atendia, de um lado, a interesses americanos imediatos, relacionados às necessidades de guerra e de aproximaçáo econômica com o Brasil; e de outro, respondia aos interesses do governo Vargas de expandir no território brasileiro a presença e a autoridade do Estado (Campos, 2006, p. 173-185). O contrato que alocava atividades do SESP no Vale do Rio Doce previa a execução de medidas de saúde e saneamento nas principais cidades localizadas ao longo do percurso da EFVM, então encampada pela Companhia Vale do Rio Doce, também criada em 1942 pelo governo Vargas (Bastos, 1993, p. 501).

O início das atividades foi marcado por dificuldades logísticas: falta de pessoal especializado, montagem da estrutura física e burocrática, constrangimentos entre o SESP, a Companhia Vale do Rio Doce e os empreiteiros, que não aceitaram de imediato a ingerência do SESP na questão da organização dos acampamentos de trabalhadores (Bastos, 1993; Campos, 2006), além da dificuldade de adaptação dos estrangeiros chegados à região.

Muito embora a documentação nos forneça detalhes sobre o processo de implantação do serviço, novamente o depoente 1 chama atenção para a dimensão cotidiana, com detalhes que expressam o despreparo da modernidade frente à natureza.

O SESP chegou, chegaram aqueles homens com aqueles chapéus de cortiça, como se vê na África, não é isso? Um chapéu branco, de cortiça, calcinha [sic] branca, etc. Quando viram aquela poeira, passava uma bicicleta levantava poeira, carroça e febre malária, malária, malária, eles não estavam preparados pra isso. Então, eles pediram socorro "mande pra aqui um epidemiologista e mande uma pessoa especializada em doenças tropicais, de países tropicais, porque nós sabemos por alto, mas isso aí a quantidade é muito grande". Era malária, leishmaniose, que come nariz, esquistossomose, horrível, e não havia tratamento muito eficaz. Então eles comunicaram lá a superintendência e a superintendência começou como se deve começar em país civilizado, mas aqui, Figueira do Rio Doce, era diferente, era preciso tratar do sujeito pra ele não morrer. (Depoente 1, 2001) 
Nos documentos, ${ }^{7}$ as condiçôes sanitárias e de saúde encontradas pelo SESP na região do Médio Rio Doce não eram das melhores: ${ }^{8}$ a malária era endêmica e parasitoses variadas acometiam a população (FSESP: Cx. 21, doc. 29 e 30; Cx. 48, doc. 42; Cx. 52, pasta 84). Os primeiros inquéritos sanitários (Campos, 2006, p. 182), ${ }^{9}$ realizados em 1943 na área delimitada, indicavam a existência de uma série de doenças (sífilis, tifo, úlcera tropical, ancilostomíase, bouba, malária e doenças nutricionais). A malária era a que mais debilitava os trabalhadores, por isso mereceu atenção especial, com distribuição de atebrina ${ }^{10}$ (Campos, 1999, p. 603-620) em larga escala. A vacinação de todos os trabalhadores contra a varíola e a febre tifoide e a assistência médica emergencial foram realizadas pelo SESP.

Os agentes do SESP, quando chegaram à cidade de Governador Valadares em 1942, encontraram o mesmo quadro adverso que caracterizava a regiấo: ausência de saneamento, incidência de endemias ${ }^{11}$ e um grave surto de malária. Juntamente com a drenagem ou o esgotamento de lagoas e outras "coleçôes de água", os agentes do SESP conduziram um amplo trabalho de eliminação de vários focos na área urbana e rural do município, com a finalidade de combater o "darling" (Amaral e Penido, 1947). ${ }^{12}$ O projeto para instalação de um sistema de fornecimento de água potável foi desenvolvido entre os anos 1944-1946 (FSESP: Cx. 33, doc. 36). Até então, a água utilizada pelos moradores da cidade era inadequada para o consumo, pois era retirada diretamente do Rio Doce, reservada de modo inconveniente em cartolas (barris) e outros vasilhames, não havendo

7 Todos os documentos citados estáo disponíveis nos arquivos da Casa de Osvaldo Cruz, mais especificamente no Fundo SESP, Divisão de Engenharia.

8 A fim de situar a atuação do SESP no Sertáo do Rio Doce nas décadas de 1940 e 1950, vale considerar que o estado sanitário desse território náo se diferenciava da situaçáo sanitária nacional e dos estados de Minas Gerais e Espírito Santo, especialmente considerando as localidades do interior.

9 Inquéritos realizados pelos médicos Henrique Penido e Eugene Payne, responsáveis pelo Programa.

10 A atebrina é uma droga química que substitui o quinino na prevenção dos sintomas da malária. A droga já era produzida, desde a década de 1920, pela Bayer alemã. Em 1942 os norte-americanos aperfeiçoaram e produziram maciçamente a atebrina.

11 A malária era a ponta de um problema mais amplo, característico das regiôes de floresta em processo de ocupação. Havia também grande incidência de febre amarela, leishmaniose e esquistossomose, completando o quadro preocupante de infestação de doenças.

12 O Anopheles darlingi foi identificado como o principal vetor da malária na região, embora existissem outros espécimes. 
maiores preocupaçóes por parte dos moradores em dar-lhe tratamento para uso doméstico. Segundo o relatório do projeto, essa situação era largamente responsável por um quadro grave de doenças, especialmente as disenterias variadas, inclusive com vários casos de óbito. A instalação do serviço de abastecimento de água abriu caminho para um projeto complementar de captação e escoamento de esgoto doméstico e de instalaçóes comerciais e públicas, iniciado em agosto de 1943, com o término previsto para final de 1944 (FSESP: Cx. 33, doc. 33).

A aprovação do projeto pela população é atestada, segundo o documento, pela construção espontânea de mais de 300 conexóes à rede de esgotos até 30 de junho de 1945. Em dezembro de 1947, foi assinado um projeto para a construção de privadas sanitárias na cidade, complementar ao projeto da instalação do serviço de escoamento de esgotos que em áreas suburbanas seria dispendioso e estruturalmente inviável. Essas áreas, que ficavam nos arredores da cidade, eram habitadas por operários das serrarias e serviços de mineração, sem condiçóes econômicas de colocar instalaçóes sanitárias em suas casas (FSESP: Cx. 48, doc. 40). Naquele ano, segundo levantamento feito pelo Serviço, 960 prédios, entre os 3.000 construídos, não possuíam instalação sanitária. "As necessidades fisiológicas são satisfeitas nas imediações das habitaçôes, muitas vezes próximo [sic] ao poço, que fornece toda água usada na casa. Daí, provavelmente, a origem dos casos de febre tifóide que surgem" (FSESP, cx 48, doc. 40).

Além desses projetos, aqui resumidamente apresentados, o SESP desenvolveu outros na cidade com a mesma orientação sanitária. Entretanto, houve também a ampliação de suas atividades para assistência médica e dentária, além de campanhas relacionadas com questóes específicas da saúde pública. A disponibilidade de serviços médicos e dentários, aliada a amplas campanhas de conscientização e educação sanitária, mudou hábitos e práticas cotidianas quanto à higiene e aos cuidados com a saúde.

A documentação e a historiografia sobre a ação sespiana tratam de um tempo marcadamente moderno, que passa a ser vivenciado no Sertão do Rio Doce, especialmente em Governador Valadares. É inegável que os projetos do SESP tiveram um papel relevante e, em grande medida, contribuíram de forma ímpar para a urbanização da cidade e do seu entorno. Contudo, a temporalidade da modernidade e a nova espacialidade redefiniam o espaço e remodelavam um território marcado por práticas tradicionais e cotidianas; 
além disso, alteravam os referenciais e as relações entre os homens e as pedras, projetando territórios existenciais diferentes dos já conhecidos.

Chama atenção o fato de o corpus documental recorrentemente deixar de fora a população e a cultura local. As doenças aparecem apartadas da humanidade. Os projetos e açôes visavam a levantar e a identificar as ocorrências endêmicas, e mesmo quando o SESP despendia esforços em prol de uma educação sanitária, o fazia sem levar em consideração as práticas cotidianas, a perspectiva de mundo da população, suas crenças e tradiçôes e, por que não dizer, até mesmo suas redes de poder, já plenamente estabelecidas.

Dessa forma, tempos e espaços delineiam territórios e territorialidades distintas e distantes. Territorialidades se estabelecem, e o cenário é alterado com base em uma rede de poder que hierarquicamente elege a modernidade e a medicina científica como única opção oferecida à população. Contudo, as narrativas nos mostram que houve resistência e que o cotidiano se revelava bem mais complexo do que fora expresso na documentação oficial do SESP.

\section{A cultura sanitária e suas narrativas: figurações do cotidiano}

A par do discurso dos projetos implementados pelo SESP, é importante ponderar o discurso internalizado pelos funcionários que atuaram nos serviços, como é o caso do depoente 2 , citado anteriormente, e do depoente 3 . $\mathrm{O}$ primeiro, dentista e um dos nomes mais significativos na implementação dos projetos de saneamento do SESP em Governador Valadares; o outro, agente sanitário que trabalhou por décadas no Serviço.

O trabalho cotidiano do agente sanitário, segundo o depoente 3, era fazer inquérito de higiene nas moradias e ao mesmo tempo fazer divulgação de hábitos de higiene e saneamento, como utilização das fossas, limpeza das áreas ocupadas e tratamento do lixo. Segundo seu depoimento, alguns moradores ficavam receosos ou mesmo não gostavam de receber os agentes sanitários por vergonha ou desconforto com a presença deles em suas moradias. Nesses casos, eram instruídos a falar com autoridade a fim de convencer o morador. Nosso depoente chama atenção para o que ele considerava uma situação vexatória. Ela ocorria quando alguma pessoa atendia ao apelo do 
guarda para procurar o Centro de Saúde e não era atendida, conforme o esperado, no horário ou na forma de tratamento. Frequentemente, essa situação acarretava reclamaçôes com o guarda que havia insistido na busca pelos serviços do SESP, culpando-o pela perda de tempo ou confiança.

Segundo o nosso informante, cada agente possuía um roteiro e um mapa da cidade para facilitar o serviço; ao fazer as visitas, os agentes faziam um itinerário que continha o endereço completo das casas que estavam sendo atendidas. Algumas pessoas tinham resistências a esse serviço por não aceitarem o acesso de desconhecidos em suas casas. Quando este era permitido, os agentes iam verificar se na casa havia banheiro, rede de esgoto, entre outros equipamentos de saneamento básico. No caso de ausência desses equipamentos, eles providenciavam e dava-se baixa naquele serviço.

O depoente 3 diz que, mesmo com as melhorias higiênicas, a população da zona rural, da periferia e até mesmo da cidade utilizava as privadas para guardar arreio dos cavalos e colocar galinhas para chocar. Ele explica que mesmo as pessoas possuindo latrinas em sua casa não tinham o costume de usá-las, pois permanecia o costume de ir "ao mato", o que "contaminava o solo (com vermes e micróbios), as pessoas que andavam descalço naquele lugar e também tudo que está ao redor”. Segundo nosso informante, muitas dessas pessoas, oriundas da zona rural, mantinham aqueles costumes e resistiam aos novos equipamentos sanitários. Não compreendiam ou desconfiavam dos divulgados 'milagres' do saneamento. O mais curioso é que esse informante afirmou que ele mesmo "não sabia nada de saneamento" antes de entrar no Serviço. Ele havia sido convencido das novas ideias, tornando-se seu divulgador.

Percebe-se, nas palavras do agente sanitário, a distância entre o projeto sespiano e a prática cotidiana. $\mathrm{O}$ território a ser saneado chocava-se com os territórios existenciais e com o habitus espacial que lhe era peculiar. Nas representaçóes e percepçóes da população, o lar era um 'território sagrado', a ser defendido e resguardado, e a privada sanitária tornava-se um 'adereço' facilmente dispensável, um espaço não praticado. $\mathrm{O}$ tempo da tradição ainda se fazia presente e, portanto, o espaço a ele relacionado não comportava e náo incorporava as mudanças anunciadas e executadas pela modernidade.

Por outro lado, o depoente 2 conta que, ao chegar do Rio de Janeiro, no início da década de 1940, sua mentalidade era mais evoluída que a da região. Sua fala remonta frequentemente às origens dos eventos relacionados 
a Governador Valadares, levando-o a conectá-los tanto à História do Brasil quanto à História Contemporânea mundial, numa busca de argumentos que pudessem justificar a ação do SESP, inclusive sua criação. Remonta à questão da História do Brasil, "tumultuada pela Revolução de 30, o Estado Novo de Getúlio Vargas”, para, em seguida, chegar à II Guerra Mundial, que "fez florescer toda a região do Médio Rio Doce", pois precisavam [os Aliados] da mica de Governador Valadares, do minério de ferro de Itabira e da borracha da Amazônia. Assim, na perspectiva do depoente 2, Getúlio assinou um acordo com os Estados Unidos e, para garantir a legitimidade do serviço de saúde pública financiado pelos americanos, deu a este uma característica "especial”, com autonomia em relação ao Ministério de Educação e Saúde ${ }^{13}$ então existente.

O Brasil se transformou em função da imposição da guerra, o que, segundo o depoente 2, explica o porquê do Serviço Especial de Saúde Pública. Para ele, o Brasil não podia ter um órgão público criado para suprir os interesses americanos relativos ao saneamento das regióes acima referidas sem ferir a soberania nacional. Entáo, uma das aplicaçóes de recursos ao Brasil, pelo acordo de Washington, foi a criação do SESP. Após a chegada do SESP, foi dada ênfase à medicina preventiva que o mundo já conhecia, diferentemente do Brasil, que conhecia somente a medicina curativa. Nosso informante explica que o Serviço conduziu à revoluçáo da saúde no Brasil.

Ao falar da situação sanitária de Governador Valadares, nosso segundo informante a descreve como sendo muito precária e com muitas endemias. Ele considera que o SESP foi muito importante para todos os moradores de Governador Valadares, e lamenta por ele não existir mais, por não ter sido adequado à estrutura jurídica e aos interesses da saúde brasileira. Em outras palavras, para o depoente 2, as mudanças ocorridas - em 1960, a transformação do SESP em Fundação SESP (ligada ao Ministério da Saúde), e finalmente sua incorporação pela FUNASA (no Governo Collor) - atenderam a novos propósitos políticos/jurídicos e a diferentes interesses e políticas públicas.

Os relatos dos dois funcionários acima mencionados (depoentes 2 e 3 ) coincidem na avaliação sobre o Serviço que, segundo eles, era muito organizado. Algumas observaçóes podem ser realçadas a partir das informaçóes coletadas. Em primeiro lugar, são comuns entre os informantes as demons-

13 O Ministério da Saúde, autônomo em relação ao da Educação, foi criado em 1953. 
trações de carinho relativo aos anos de trabalho na agência. De modo geral, eles não relatam problemas, erros ou desmandos e nem mesmo conflitos entre o SESP, a sociedade e o governo. Toda ação tende a ser descrita pelos depoentes como muito bem organizada, e eles revelam um sentimento de lealdade ao SESP. Há um destaque frequente em relação aos bons salários pagos, em comparação àqueles da cidade de Governador Valadares e regiáo, e a isso agregam a posiçáo social distinta que os funcionários conquistaram.

Para além de questóes financeiras e sociais, percebe-se, nas falas dos funcionários, uma apropriação do discurso técnico-científico incutido a partir dos cursos oferecidos pelo SESP. Uma análise mais cuidadosa desses depoimentos mostra como pessoas comuns se transformavam em agentes de mudança, propondo melhorias sanitárias que até bem pouco tempo eram novidades até para eles. Outra fala que é comum entre os depoentes é o reconhecimento da atuação do SESP trazendo melhorias para a cidade e regiáo.

As referências ao SESP nos textos de memorialistas locais e no depoimento dos antigos funcionários entrevistados tratam-no com a deferência dirigida à autoridade ou ao benfeitor. São comuns os elogios à sua atuação e à proposta 'moderna' para a saúde e o saneamento de áreas urbanas e rurais. Tais mençôes são afirmativas da capacidade e competência do Serviço e de seus técnicos, dos benefícios realizados para as cidades atendidas, tais como a erradicação da malária, tratamento de outras enfermidades e implantação de serviços para o tratamento de água e esgoto. Nesses discursos, a ação do SESP é digna dos melhores louvores e são raros os questionamentos e críticas. Em trabalhos acadêmicos mais recentes sobre o Médio Rio Doce, a ação do SESP é reconhecida como um dos fatores que impulsionaram o desenvolvimento regional entre as décadas de 1940/1950. Há uma correlação entre desenvolvimento/SESP, porém de forma pontual, sem aprofundamentos sobre as atividades realizadas ou os métodos utilizados.

Percebemos, portanto, nas palavras dos informantes, uma figuração. Nessa rede, os indivíduos vivenciam um contexto de mudanças e internalizam um discurso. Para o projeto sespiano, a mudança deveria ser rápida, mas as figuraçóes tradicionais, entranhadas nas práticas cotidianas, as tornavam lentas e, em alguns casos, superficiais. Na dinâmica social, as razóes individuais impediam o uso da privada sanitária em virtude dos comentários dos vizinhos ou da desconfiança dos milagres do saneamento. O simples abandono de todas as práticas anteriores se refletiria numa redefinição 
das funções sociais já estabelecidas, rompendo o contrato social em vigor, reordenando as relaçóes de poder e, por conseguinte, as territorialidades em curso.

As narrativas dos informantes revelam a difícil conciliação entre figuraçóes que passam a conviver numa dada realidade em transformação acelerada. Os projetos sespianos transformavam o cenário do sertão e criavam pontes inimagináveis, atrelando tempos e espaços antes distantes. Através dos discursos e documentos, só temos como acompanhar o plano implementado e o sucesso alcançado pelo serviço de saneamento e a educação sanitária. É através da História Oral e das narrativas que percebemos uma tessitura bem mais complexa, envolta em tramas ora modernas, ora tradicionais, com noçôes temporais distintas, tentando acomodar um tempo acelerado e um espaço dinâmico em meio a um habitus permeado pelo fantástico das raízes, rezas e bendiçóes.

\section{Considerações finais}

Não há como negar que, para o Médio Rio Doce, as ações do SESP entre as décadas de 1940 e 1950 propiciaram o ordenamento dos territórios urbanos, o saneamento rural, a erradicação da malária, a contenção de outras endemias e a imposição das práticas médicas científicas. De fato, foram criadas as condiçóes territoriais para a região receber e expandir os grandes investimentos de capital (mineração, siderurgia, indústria madeireira). Ao mesmo tempo, favoreceu sua confirmação como fronteira agrícola, realçando o papel do Serviço na consolidação e no fortalecimento da presença do Estado (state building) nessa região.

Também há que se reconhecer que, para a população atendida, tais açóes provocaram alteraçóes nas práticas de saúde, nos costumes e nos valores culturais e uma (re)organização do espaço. O discurso de ciência em que o SESP se apoiava procurava sistematizar uma pedagogia sanitária de intervenção na comunidade. Nessa dinâmica, as visitadoras e os guardas sanitários se apropriaram do discurso técnico-científico e foram eles mesmos agentes de mudança "por dentro", uma vez que eram membros das comunidades atendidas ou tinham o mesmo perfil. Para os entrevistados, em função desse 
trabalho, o SESP foi uma benesse do poder público, confirmando a tese de que a disponibilização de bens públicos de saúde não foi usufruída como conquista social.

É nesse sentido que podemos falar de um objeto transversal que recoloca o papel da História Oral e da interdisciplinaridade. A cultura sanitária, especialmente expressa na oralidade, perpassa os meandros do território físico, demarcado na região do Médio Rio Doce de acordo com os documentos oficiais. Entretanto, também remete à outra concepção de território imerso em um contexto sócio-histórico cercado por inúmeras relações de poder, que vão desde as estabelecidas entre os habitantes autóctones e os 'pioneiros ${ }^{14}$ àquelas que vinculavam os interesses americanos à região. Essa segunda concepção de território, de cunho relacional, nos dá uma dimensão mais apurada das territorialidades que ora se chocavam, ora se complementavam no processo de saneamento que se desenrolava principalmente das áreas centrais em direção à periferia da cidade de Governador Valadares. Simbolicamente, o território atendido pelo SESP era visto de forma global e incluía a cidade, mas em função das múltiplas territorialidades a realidade fornecia novos contornos aos projetos implementados. As informaçóes e a educação sanitária pretendidas pelo SESP não desconfiguravam as práticas cotidianas da população da periferia que, mesmo assistida, mantinha seus costumes. Os territórios existenciais teimavam em permanecer em meio à modernidade que se apresentava propondo um novo ritmo, um tempo mais acelerado palmilhado de novas práticas cotidianas.

A territorialidade dominante dos 'pioneiros' e da medicina científica, revestida de modernidade, sobrepunha-se à territorialidade da população menos abastada, que em muitos aspectos não contestou o discurso civilizador. Pelo contrário, em muitas ocasiôes, internalizou-o ao mesmo tempo em que assimilou seus atores mais significativos, oriundos das famílias ilustres e bem-sucedidas, assim como ecoou o discurso sanitário, sem contudo incorporá-lo como habitus. Nessa 'teia de significados', cabe interpretar os motivos do SESP realçados nas palavras do depoente 2, o sentido cotidiano dessa mesma ação, pontuada pelo depoente 3, e também cabe verificar as negociaçóes dessas narrativas amarradas nos vários

14 Autodenominação de antigos moradores, chegados anteriormente, que se assenhorearam de terras e riquezas, tornando-se a elite local. 
discursos, dentre os quais o dos documentos oficiais, num cenário que ora se apresenta como o Congo, como pontua o depoente 1, e ora se aproxima do tempo da natureza.

Por isso, falamos de um território mutifacetado, que ganha sentido na experiência da população e exige da análise histórica um esforço contínuo de contraponto entre suas várias escalas espaciais e temporais. Numa perspectiva mais ampla, a ação sespiana não pode ser enquadrada numa estrutura, uma vez que não se pode falar de uma ação homogênea. Estamos, portanto, lidando com um agenciamento cujo conjunto de partes interage negociando sentidos e configurando açóes e intenções. Nesse cenário de múltiplos territórios, a modernidade da medicina científica não tem o mesmo sentido para os demais habitantes e nem o desenvolvimento e a urbanização empreendidos a partir dos projetos implementados pelo SESP são incorporados ao cotidiano da mesma forma. O SESP tinha como modelo de saneamento o padrão internacional, mas a grande maioria da população tinha como modelo o próprio vizinho, que muitas vezes podia ridicularizar o uso da privada sanitária. O reordenamento do espaço urbano, citado acima, embora alterasse visivelmente o território, náo desagregava as práticas de manter o lixo nas ruas, de usar o mato para as necessidades fisiológicas e as privadas para guardar arreios e galinhas, ou até mesmo de achar a água do Rio Doce mais confiável que aquela que chegava através de um sistema de abastecimento.

Portanto, há que se ressaltar a importância da História Oral e das narrativas para tratar a cultura sanitária. Em outras palavras, é na oralidade que as tramas temporo- espaciais se revelam na sua dinâmica e dramaticidade. É nas falas da população que percebemos os vários discursos, as múltiplas territorialidades constituídas, as figuraçóes e o fantástico encontro entre a tradição e a modernidade.

\section{Fontes orais}

Arquivo do Programa de Memória do Vale do Rio Doce - PMVRD/Univale.

- Entrevista concedida pelo Depoente 1 ao Professor Haruf Salmen Espindola, em 14/12/2001. 
- Entrevista concedida pelo Depoente 2 à Professora Maria Terezinha Bretas Vilarino, em $29 / 05 / 2008$.

- Entrevista concedida pelo Depoente 3 à Professora Maria Terezinha Bretas Vilarino, em $14 / 12 / 2007$.

\section{Fontes escritas}

Arquivo da Casa de Osvaldo Cruz/Fiocruz - Fundo SESP (FSESP)

Seção Divisão de Engenharia, caixas 21, 33, 48 e 52.

FSESP: Cx. 21, doc. 29 e 30, respectivamente: Tratamento e profilaxia da malária pela Metoquina (Atebrina), na área da denominada "Linha Abaixo" - Programa do Rio Doce. Projeto: RD-LAB-23 e Inspeção sanitária na área Linha Abaixo - Programa do Rio Doce. Projeto: RD-LAB-22

FSESP, Cx. 52, pasta 84 - Inspeção sanitária na Área Linha Central da EFVM nos estados do Espírito Santo e de Minas Gerais, entre Colatina e Governador Valadares. Projeto: RD-LCE-22.

FSESP, Cx. 48, doc. 42 - Drenagem para controle de malária - Área Linha Acima - EFVM. Projeto: RD-LAC-10).

FSESP, caixa 33, documento 36 - Projeto paralelo de instalação de serviço de esgotos e Sistema de abastecimento d'água em Governador Valadares, MG. Projeto: RD-GVA-7-A

\section{Fontes impressas}

ESPINDOLA, Haruf Salmen. Associação Comercial de Governador Valadares - Sessenta anos de história. Governador Valadares: ACGV, 1999.

ESPINDOLA, Haruf Salmen. Sertão do Rio Doce. Bauru: Edusc, 2005. - A história de uma formação socioeconômica urbana: Governador Valadares. Varia História, Departamento de História, Programa de Pós-Graduação em História, Faculdade de Filosofia e Ciências Humanas, Universidade de Minas Gerais, Belo Horizonte, n. 19, p. 154, 1998. 


\section{Referências}

AMADO, J. Construindo mitos: a conquista do Oeste no Brasil e nos EUA. In: PIMENTEL, S. V. e AMADO, J. (Org.). Passando dos limites. Goiânia: Ed. UFG, 1995.

$145-151$

. Região, sertão, nação. Estudos Históricos, Rio de Janeiro, v. 8, n. 15, 1995. pp

AMARAL, A. D. F.; PENIDO, H. M. Distribuição dos anofelinos no vale do Rio Doce (Percurso da E. F. Vitória-Minas) - espécies transmissoras da Malária. Revista do SESP, Ano I, Rio de Janeiro, n. 01, p. 163-178, 1947.

BAKHTIN, M. Problemas da Poética de Dostoiévski. 3. ed. Tradução de Paulo Bezerra. Rio de Janeiro: Forense Universitária, 2002.

BORGES, M. E. L. Utopias e contra-utopia: movimentos sociais rurais em Minas Gerais (1950-1964). Dissertação de Mestrado. Belo Horizonte: UFMG, 1988. PPGHIS/UFMG

. Representações do universo rural e luta pela reforma agrária no Leste de Minas

Gerais. Revista Brasileira de História, São Paulo, v. 24, n. 47, 2004 pp 303-326.

BASTOS, N. C. B. SESP/FSESP: 1942 - evolução histórica - 1991. Recife: Comunicarte, 1993.

BRUNER, J. Atos de significação. Porto Alegre: Artes Médicas, 1997.

CAMPOS, A. L. V. de. Políticas Internacionais de Saúde na Era Vargas: o Serviço Especial de Saúde Pública, 1942-1960. Rio de Janeiro: Fiocruz, 2006.

. Combatendo nazistas e mosquitos: militares norte-americanos no Nordeste brasileiro (1941-45). História, Ciências, Saúde-Manguinhos, (3): 603-20, nov. 1998-fev.1999.

CERTEAU, M. A Invenção do Cotidiano. 17. ed. Petrópolis: Vozes, 2011. (Volume I).

COHN, G. (Org.). Max Weber. São Paulo: Ática, 1991.

COLLIOT-THÉLÈnE, C.. Max Weber e a História. São Paulo: Brasiliense, 1995.

CUNHA, A. M. Vila Rica - São João del Rey: as voltas da cultura e os caminhos do urbano entre o século XVIII e o XIX. Dissertação de Mestrado. Niterói: Programa de Pós Graduação em História/UFF, 2002.

DARTON, R. O Grande Massacre dos gatos e outros episódios da história cultural francesa. Rio de Janeiro: Graal, 1996.

DELGADO, L. de A. N. História oral e narrativa: tempo, memória e identidade. História Oral, 6, 2003.pp. 20-25

ELHAJJI, M. Memória coletiva e espacialidade étnica. Galáxia, n. 4, 2002.pp 177-191 
ELIAS, N.. O processo civilizador. Tradução de Ruy Jungmann. Rio de Janeiro: Zahar, 1990. . A sociedade dos indivíduos. Tradução de Vera Ribeiro. Rio de Janeiro: Zahar, 1994. . A sociedade de corte. Tradução de Pedro Sussekind. Rio de Janeiro: Zahar, 2001 .

ELIAS, N. e SCOTSON, J. Os estabelecidos e os outsiders. Tradução de Vera Ribeiro. Rio de Janeiro: Zahar, 2000.

ELIAS, N. Sobre o tempo. Tradução de Vera Ribeiro. Rio de Janeiro: Zahar, 1998.

ERRANTE, A. Mas afinal, a memória é de quem? Histórias Orais e Modos de Lembrar e Contar. In: História da Educação. Pelotas: Editora da UFPel, 2000.

ESPINDOLA, H. S. Sertão do Rio Doce. Bauru: EDUSC, 2005.

GEERTZ, C. A interpretação das culturas. Rio de Janeiro: Zahar, 1978.

HAESBAERT, R. O Mito da Desterritorialização. Do 'Fim dos Territórios' à Multiterritorialidade. Rio de Janeiro: Bertrand Brasil, 2006.

HALBWACHS, M. A memória coletiva. São Paulo: Vértice, 1990.

HARVEY, D. Condição Pós-Moderna. São Paulo: Loyola, 1993.

HOLZER, W. Memórias de viajantes: paisagens e lugares de um Novo Mundo. GEOgraphia - Ano II - n. 3, 2000. pp. 111-122

LIMA, N. T. Um sertão chamado Brasil. Rio de Janeiro: Renavan/Iuperj-Ucam, 1999.

Missōes civilizatórias da República e interpretação do Brasil. História, Ciências, Saúde-Manguinhos. Rio de Janeiro, 2008. Disponível em: <http://www.scielo.br/scielo. php?script $=$ sci_arttext\&pid $=$ S010459701998000400010\&lng $=$ en $\& n r m=i s o>$. Acesso em: 11 jun. 2008. pp. 163-193

LOWENTHAL, D. Geography, experience and imagination: towards a geographical epistemology. Annals of the Association of American Geographers. 51 (3), 1961.pp 241-260

MASSEY, D. Pelo Espaço: uma nova política de espacialidade. Rio de Janeiro: Bertrand Brasil, 2009.

PENA, B. Minas e Rio Grande do Sul: estado da doença e estado de saúde. Revista dos Tribunais: Rio de Janeiro: 1918.

PIMENTA, D. J. A Vale do Rio Doce e sua história. Belo Horizonte: Vega, 1981.

RICOEUR, P. A memória, a história, o esquecimento. Campinas: Editora da Unicamp, 2007.

ROCHA, A. L. C. da; ECKERT, C. A memória como espaço fantástico. Iluminuras. v. 1, n. 1, 2000. pp. 1-15

SACK, R. D. Human territoriality. Cambridge: Cambridge University Press, 1986. 
SIMAN, L. M. de C.. A história na memória: uma contribuição para o ensino da História de cidades. Dissertaçáo de Mestrado. Belo Horizonte: UFMG, 1988. Pós-Graduação em Educação da UFMG

TUAN, Y. F. Espaço e lugar: a perspectiva da experiência. Sáo Paulo: Difel, 1983.

VILARINO, M. T. B. Entre lagoas e florestas: atuação do Serviço Especial de Saúde Pública (SESP) no saneamento do Médio Rio Doce (1942 e1960). Dissertaçáo de Mestrado. Belo Horizonte: UFMG, 2008. PPGHIS/UFMG

Resumo: Pretende-se abordar a cultura sanitária do Sertão do Rio Doce e, de forma mais específica, da cidade polo dessa região, Governador Valadares. A cidade em questão, assim como a esmagadora maioria das cidades e distritos do Sertão de Minas Gerais, apresentava um cenário calamitoso, permeado por endemias, epidemias e ausência quase completa dos princípios básicos de saneamento até o início da década de 1940. Um acordo bilateral entre Estados Unidos e Brasil deu início a um projeto de saneamento do Médio Rio Doce, área considerada estratégica para a extração de vários minérios largamente utilizados em artefatos bélicos. Nesse sentido, a História Oral será incorporada ao exercício enquanto metodologia de coleta e processamento de narrativas. Ao acessar memórias, a História Oral também entrelaça categorias distintas, tecendo uma trama complexa envolvendo a memória, a história, o tempo e o espaço.

Palavras-chave: História Oral, tempo-espaço, sertão, cultura sanitária, SESP.

\section{Sanitation culture from the oral history point of view: Sertáo do Rio Doce in its multiple temporo-spatial perceptions}

Abstract: Governador Valadares (Brazil) as well as majority of surrounding cities and villages until the first half of the $20^{\text {th }}$ century - at that time named Sertão of Minas Gerais, i.e. deep countryside - presented in terms of health dimensions a tragic scenario of endemics and epidemics diseases nothing saying of the absence of almost complete health basic organization and services. By the end of this time, an agreement between United States and Brazil was concluded having in mind the sanitation of the area, since this area was considered strategic because of the rich mineral resources mainly used in weapons and war. Various activities were so funded and deployed to carry out an experience of teaching and learning on new health culture: new practices of health care and sanitation. This article deals with Oral History as an exercise and as a methodology of collecting and data handling in narratives having an special focus on memories of health practices. Of course one must have in mind that when he gets in touch with these memories of Oral History one will find a skein of distinct categories. All this make a complex fabric where one finds different kinds of memories, history, space and time issues.

Keywords: Oral History, space-time, Brazilian countryside, Health culture, Health Agencies (SESP).

Recebido em: 15/03/2012

Aprovado em: 02/07/2012 